\title{
Evidence for the presence of kinetin in DNA and cell extracts
}

\author{
Jan Barciszewski ${ }^{b}$, Gunhild E. Siboska ${ }^{\mathrm{a}}$, Bent O. Pedersen ${ }^{\mathrm{a}}$, Brian F.C. Clark ${ }^{\mathrm{a}, *}$, \\ Suresh I.S. Rattan ${ }^{\mathrm{a}}$
}

"Department of Molecular and Structural Biology, Aarhus University, DK-8000 Aarhus-C, Denmark
'Institute of Bioorganic Chemistry, Polish Academy of Sciences, Noskowskiego 12, 61704 Poznan, Poland

Received 28 June 1996

\begin{abstract}
In contrast to the current view that kinetin $\left(N^{6}\right.$. furfuryladenine) is an unnatural and synthetic compound, we have detected it in commercially available DNA, in freshly extracted cellular DNA from human cells and in plant cell extracts by two independent methods. First, we discovered that $N^{6}$-furfuryladenine has electrochemical properties that can be applied for monitoring this modified base by a HPLC/UV/EC method. Second, we have confirmed electrochemical assignments by mass-spectrometric analysis. A pathway of kinetin formation is proposed in which the formation of furfural by oxidative damage of the deoxyribose moiety of DNA is followed by its reaction with adenine residues to form $N^{6}$-furfuryladenine. Since this modification can lead to mutations, the odd DNA base has to be removed by repair enzymes.
\end{abstract}

Key words: 6-Furfuryladenine; Kinetin; DNA damage; HPLC/UV/EC

\section{Introduction}

About 40 years ago, kinetin ( $N^{6}$-furfuryladenine, 6-FAde) was isolated from autoclaved herring-sperm DNA and was shown to act as a cytokinin plant growth hormone [1,2]. It has been assumed to be an artificial rearrangement product of the autoclaving of DNA and not to occur naturally $[2,3]$. Since its discovery, this compound has been widely used as a cytokinin in various aspects of plant science, including its applications in plant biotechnology and cell biology [4]. Recently, kinetin has been shown to delay the onset of many age-related characteristics that appear in normal human skin fibroblasts undergoing ageing in vitro [5] and prolongs the lifespan of the fruit fly [6]. Because of the intriguing effects of kinetin, we decided to reinvestigate the question concerning its origin and its biological properties by using the techniques of electrochemical (EC) and mass spectrometric detection with very high sensitivity.

Many biological substances are electrochemically active and they can be easily oxidised or reduced by applying a suitable potential. Some DNA adducts are electrochemically very active, while the basic components of nucleic acids generally are not [7]. For example, 8-hydroxydeoxyguanine can be detected electrochemically at a level of one adduct in $10^{5}-10^{6}$ normal bases in microgram quantities of DNA [7,8]. Therefore, we decided to check the EC activity of kinetin and whether this property could be useful for its detection.

We have found that kinetin has EC properties which can be used for its detection in natural products. Using high-per-

*Corresponding author. Department of Chemistry, Aarhus University, DK-8000 Aarhus-C, Denmark, Fax: (45) 86196199

E-mail: clark@biobase.dk formance liquid chromatography (HPLC/UV) combined with an EC detector, we have detected kinetin as a component of DNA as well as in plant cell extracts. These findings were confirmed by mass-spectrometric analysis. We also propose a pathway of kinetin formation in which oxidative damage to the deoxyribose moiety yields furfural as a primary DNA damage product which modifies adenosine in DNA. We also suggest explanations for the biological activity of kinetin as a potent superoxide dismutase.

\section{Material and methods}

2.1. Extraction of kinetin from dried coconut under acidic conditions Commercially available dried coconut chunks $(50 \mathrm{~g})$ were homogenised in $10 \mathrm{ml} 0.2 \mathrm{~N} \mathrm{HCl}$ at $50^{\circ} \mathrm{C}$ overnight. The homogenate was brought up to $\mathrm{pH} 8$ with $\mathrm{NaOH}$ and treated with $5 \times 100 \mathrm{ml}$ watersaturated ethyl acetate. The extract, which contained mainly fatty acids, was analysed on a HPLC/UV/EC system after evaporation of the solvent.

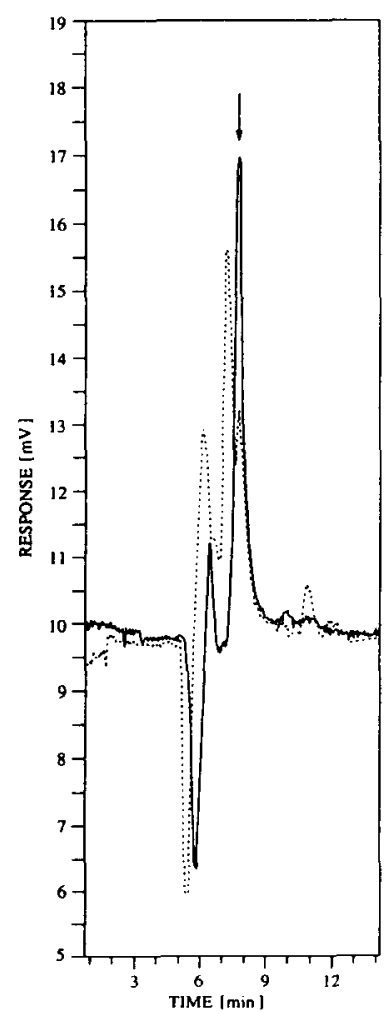

Fig. 1. HPLC/UV/EC analysis of commercially available kinetin. The peak corresponding to kinetin is marked with an arrow. UV profile (—); EC (electrochemical) profile $(\cdots)$. 
2.2. Extraction of kinetin from dried coconut under neutral conditions Commercially available dried coconut chunks $(150 \mathrm{~g})$ were extracted directly with $1000 \mathrm{ml}$ ethyl acetate saturated with water. After evaporation, a sample was analysed on a HPLC/UV/EC system and by mass spectrometry.

\subsection{Extraction of kinetin from DNA}

Calf thymus DNA (130 mg; Sigma, type 1) was dissolved in $6 \mathrm{ml}$ $0.2 \mathrm{HCl}$ and incubated for $2 \mathrm{~h}$ at $50^{\circ} \mathrm{C}$. Extraction with $4 \times 50 \mathrm{ml}$ water-saturated ethyl acetate was carried out from neutral solution. In addition, freshly isolated DNA $(11 \mu \mathrm{g})$ from human skin fibroblast cultures [5] was treated with $0.5 \mathrm{ml} 0.2 \mathrm{~N} \mathrm{HCl}$ and incubated for $2 \mathrm{~h}$ at $50^{\circ} \mathrm{C}$. Under these conditions DNA is totally soluble. The hydrolysate was injected into the HPLC column without further purification or extraction.

\subsection{High-performance liquid chromatography analysis}

The analysis was carried out on a Gilson HPLC/UV system connected to an electrochemical detector (Coulochem II, ESA Inc.. USA) working at a potential of $650 \mathrm{mV}$. The Vydac column $(3.3 \times 150 \mathrm{~mm})$ equipped with a pre-column was equilibrated and eluted with buffer containing $12.5 \mathrm{mM}$ citric acid, $25 \mathrm{mM}$ sodium acetate, $30 \mathrm{mM}$ sodium hydroxide, $10 \mathrm{mM}$ acetic acid and $4 \%$ methanol. Effluent from the column was passed first through the UV cell and then through the EC detector. Owing to the dead volume of the connecting tube, the EC peak was always shifted by 0.6 min compared with the UV peak. This shift, deduced from EC spectra, was identical to that previously observed in 8-hydroxydeoxyguanosine analysis with the same analytical system [8]. Turbochrom software was employed for monitoring the UV and EC spectra simultaneously. Commercially available kinetin was purchased from Serva (Germany) and was analysed without further purification.

\subsection{Mass-spectrometric analysis}

MS analyses were performed by direct inlet of the samples to VG Trio-2 machine (UK). Ionisation was achieved by electron impact $(70$
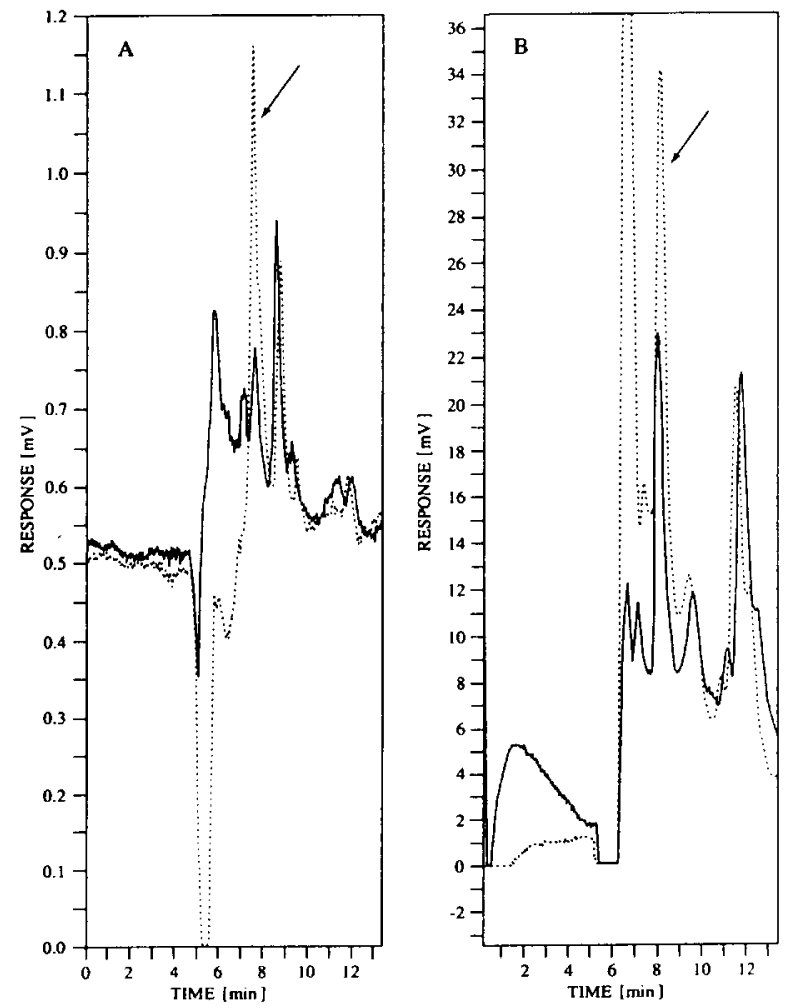

Fig. 2. HPLC/UV/EC analysis of the acidic extract of coconut chunks. Arrows identify the kinetin peak. (A) UV and (B) EC profiles of the extract. ( $\longrightarrow$ ) The extract only; $(\cdots)$ the extract co-injected with $1.8 \mathrm{nmol}$ kinetin.
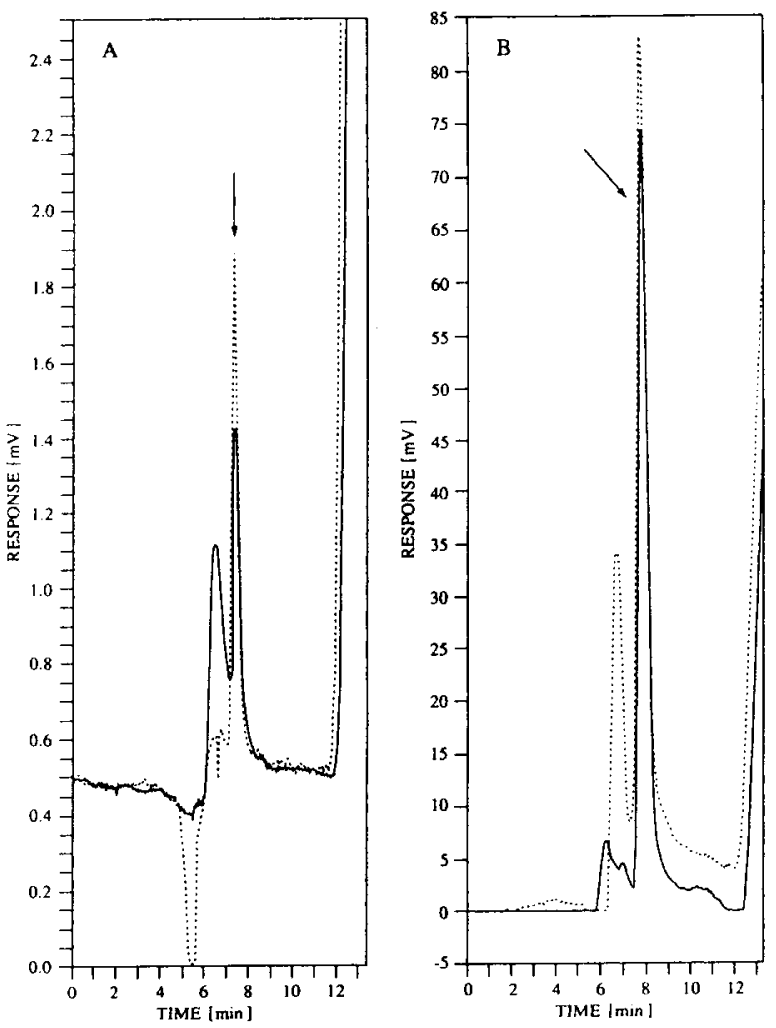

Fig. 3. HPLC/UV/EC analysis of the acidic treatment of commercially available DNA. (A) UV and (B) EC profiles of nucleic acid bases (purines) liberated during acidic treatment and extracted with ethyl acetate. (- The extract only; $(\cdots)$ the DNA extract coinjected with $1.8 \mathrm{nmol}$ kinetin.

EV). The ion source was at $200^{\circ} \mathrm{C}$ and heating of the sample was carried out up to $300^{\circ} \mathrm{C}$

\section{Results and discussion}

Kinetin has remarkable biological properties which include stimulation of plant growth, retardation of leaf senescence, modulation of the response of plants to various environmental stresses $[3,4]$ and, discovered more recently, delaying of the onset of ageing in human cells in culture [5] and in insects [6]. Until now, kinetin has been believed to be an artefactual cytokinin originating from the autoclaving of herring-sperm DNA [1] or formed on storage of DNA over a long period of time [2]. Using the HPLC/UV/EC system we have detected kinetin both as a naturally occurring component of DNA and in a plant cell extract. Fig. 1 shows the profiles of UV absorbance at $260 \mathrm{~nm}$ and the EC signal on the chromatogram of commercially available kinetin, which coincide. Since the adenine residue is not electrochemically active by itself in selected range of potential, it means that the EC properties of kinetin are due to the $N^{6}$-furfuryl substituent. This conclusion is supported by other observations in which the EC properties of the furfuryl residue have been used in polarographic assay of furfural detection [9].

As can be seen in Fig. 1, the commercial sample of kinetin, apparently pure by UV-spectral analysis, is contaminated with some impurities of high EC response. By injection of different amounts of kinetin into the HPLC/UV/EC system we were able to obtain a linear standard curve in the concentration 

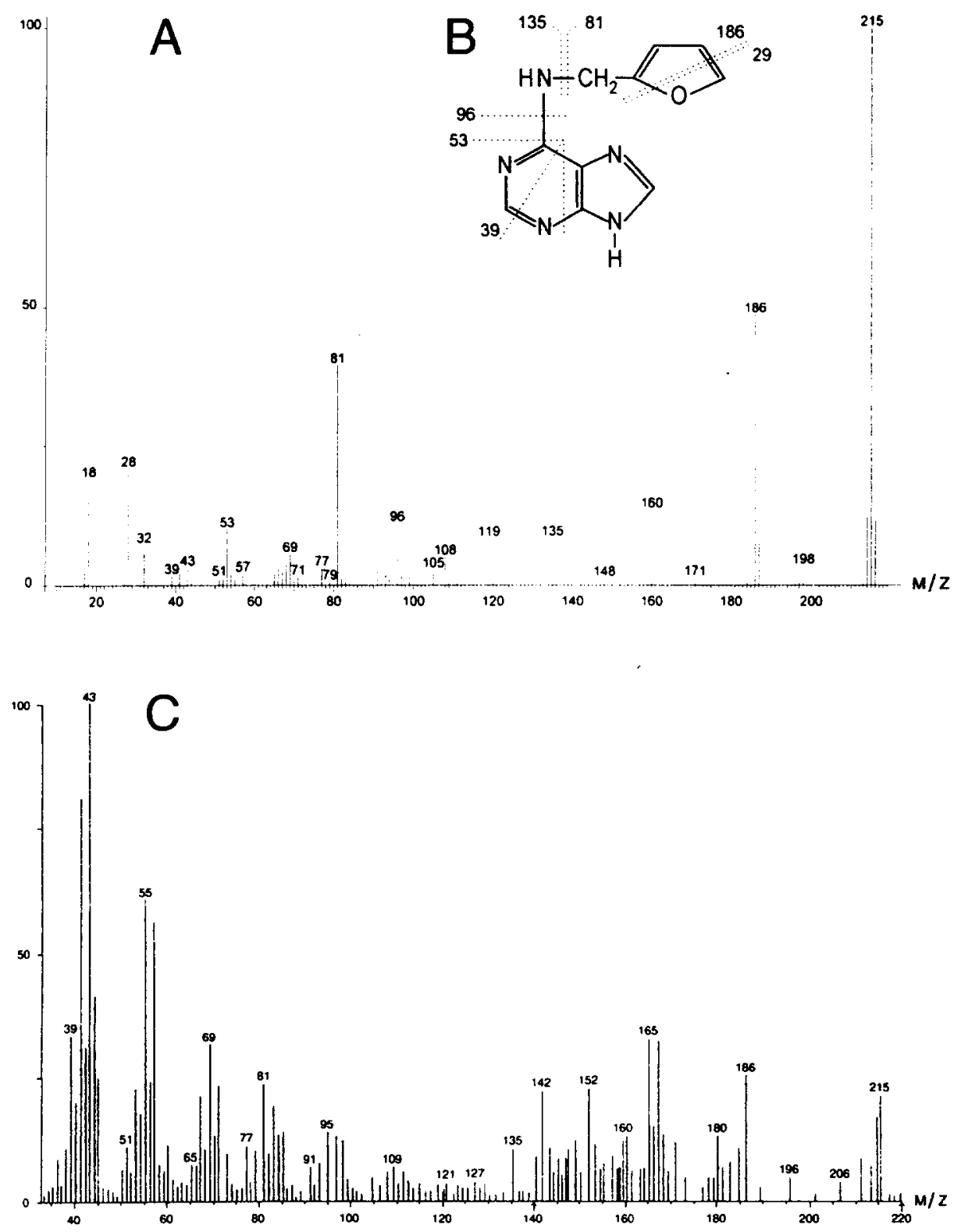

Fig. 4. Mass spectra and fragmentation of $N^{6}$-furfuryladenine. (A) commercial product, (B) fragmentation of the molecules, (C) kinetin released from DNA.

range of $1.5-4.0 \mathrm{nmol}$, which was necessary for calculation of the amounts of kinetin on the basis of UV and EC peaks (data not shown). From these data we calculate that the EC peak area of $150 \mu \mathrm{V} / \mathrm{s}$ corresponds to $1 \mathrm{pmol}$ of kinetin. This value depends strongly on parameters $(\mathrm{mV})$ of the $\mathrm{EC}$ detectors, and it varies for different EC cells. Having established this new method, we analysed extracts (acidic and neutral $\mathrm{pH}$ ) from coconut and observed that kinetin is present at a concentration of $0.1 \mathrm{ng}$ per $\mathrm{g}$ dried coconut material (Fig. 2). The same type of analysis showed that kinetin is present in commercially available calf thymus DNA (Fig. 3) and in freshly extracted DNA from human cells in culture (data not shown). Therefore, it is clear that occurrence of kinetin is not just a methodological artefact.

Since these results show the presence of kinetin as a new modified base in DNA for the first time, they need to be confirmed by some other independent method. Therefore, we turned to mass spectrometric (MS) analysis. Direct inlet of the commercial sample of DNA and of that isolated from natural sources yielded a spectrum with molecular signal of 215 mass units (Fig. 4A), which corresponds to the kinetin spectrum both deposited in the MS Library [10] and to our own recorded under the same conditions. In these spectra, there are three very characteristic signals at m/e 186, 135 and 81 . The first one corresponds to fragmentation of a five-membered ring sugar by releasing 29 mass units, the second one identifies adenine and the third one appears by breaking the N-C bond in the side chain of 6-furfuryladenine and releasing the furfuryl group (Fig. 4B). The same type of sample fragmentation was found in the mass spectra of the material liberated by treatment of commercially purchased DNA sample at $\mathrm{pH} 2$ (Fig. 4C). It is known that under such conditions the glycosyl bond of purine nucleotides is labile. Thus, the above experimental data from HPLC/UV/ 
EC analyses and mass spectrometry measurements showed unequivocally that $N^{6}$-furfuryladenine is a component of DNA.

The most probable way for kinetin synthesis is the reaction of furfural with an adenine residue on DNA level (Barciszewski et al., manuscript in preparation). This is because it has been shown that furfural is formed during the oxidative damage of DNA by hydroxylation of the $\mathrm{C}^{\prime}$ ' of deoxyribose $[11,12]$. These observations clearly explain why $N^{6}$-furfuryladenine has been found only in stored samples of DNA after autoclaving but not in freshly prepared DNA [1,2]. The proposed mechanism for the formation of kinetin links, for the first time, this modified base with oxidative damage processes occurring in the cells. Thus, kinetin can also be used as a marker of oxidative damage of DNA, like many other modified bases, such as thymine glycol and 8-hydroxydeoxyguanosine $[7,8]$.

The crystal structure of kinetin, solved long ago, makes it clear that formation of Watson-Crick hydrogen bonds with this base would be impossible, because of the conformation of the furan ring, which allows only the Hoogsteen type of interaction [13]. Furthermore, since we have found free kinetin in coconut, it is obvious that the DNA containing kinetin is enzymically repaired. One of the repair enzymes could be the eukaryotic DNA polymerase $\beta$, which catalyses DNA synthesis during base-excision repair and catalyses the release of 5'-terminal deoxyribose phosphate residues from excised apurinic-apyrimidinic sites [14-16]. Such a conclusion is supported by the considerable incorporation of $\left[{ }^{3} \mathrm{H}\right]$ uridine into cultures of fibroblasts after administration with the lowest doses of kinetin [17]. It has also been observed that kinetin at low concentration $\left(10^{-6}-10^{-4} \mathrm{M}\right)$ enhanced the germinative capacity of Lupin multilupa seeds as monitored by the incorporation of $\left[{ }^{14} \mathrm{C}\right]$ adenine into DNA [18]. Finally, there are also reports that showed incorporation of kinetin into RNA $[19,20]$.

Analysis of our results and those from the literature suggests that repaired kinetin can serve the cell in two distinct ways. First, it can induce the synthesis of repair enzymes which remove modified bases from DNA [21-23] and/or are involved in protection against oxygen stress [22]. Second, its complex with copper(II) initiates superoxide dismutase, in that the kinetin-Cu(II) complex catalyses $\mathrm{O}_{2}^{-}$dismutation very efficiently at physiological $\mathrm{pH}$, with a turnover of $2.7 \times 10^{-9} \mathrm{~mol}$ per s [24-26]. These properties can help one to understand why exogenously added kinetin to various cells has several positive effects, including anti-ageing effects on them $[5,6]$

Acknowledgements: Our thanks are due to Dr. Paul Woolley for critical reading of the manuscript.

\section{References}

[1] Miller, C.O., Skoog, F., Van Saltza, M.H. and Strong, F.M. (1955) J. Am. Chem. Soc. 77, 1392.

[2] Miller, C.O., Skoog, F., Okumura, F.S., Von Saltza, M.H. and Strong, F.M. (1956) J. Am. Chem. Soc. 78, 1375-1380.

[3] Kaminek, M. (1992) Biotechnology 10, 159-164.

[4] Binns, A.N. (1994) Annu. Rev. Plant Physiol. Plant Mol. Biol. $45,173-196$

[5] Rattan, S.I.S. and Clark, B.F.C. (1994) Biochem. Biophys. Res. Commun. 201, 665-672.

[6] Sharma, S.P., Kaur, P. and Rattan, S.I.S. (1995) Biochem. Biophys. Res. Commun. 216, 1067-1071.

[7] Park, J.W.. Cundy, K.C. and Ames, B.N. (1989) Carcinogenesis $10,827-832$.

[8] Barciszewski, J., Rattan, S.I.S., Siboska, G.E., Otzen, D.E. and Clark, B.F.C. (1993) FEBS Lett. 318, 186-188.

[9] Koen, E. (1989) Prob. Khig. 14, 127-137.

[10] US Dept of Commerce. Technology Administration, National Institute of Standards and Technology. Standard Reference Data Program, Gaithensburg. MD, Edition January, 1995.

[11] Pratviel, G., Pitie, M., Bernadou, J. and Meunier, B. (1991) Nuel. Acids Res. 19, 6283-6288.

[12] Pratviel, G., Pittie, M., Bernadou, J. and Meunier, B. (1991) Angew. Chem. Int. Ed. Eng. 30, 702-704.

[13] Soriana-Garcia, M. and Perthasarathy, R. (1977) Acta Crystallogr. B33, 2674-2677.

[14] Matsumoto, Y. and Kim, K. (1995) Science 269, 699-701.

[15] Wilson III, D.M., Tekeshita, M., Grollman, A.P. and Demple, B. (1995) J. Biol. Chem. 270, 16002-16007.

[16] Sancar, A. (1995) J. Biol. Chem. 270, 15915-15918.

[17] Kowalska, E. (1992) Fol. Morphol. 51, 109-118.

[18] Morales, C., Cusido, R.M. and Serano, M. (1987) Rev. Esp. Fisiol. 43, 87-93.

[19] Murai, N., Taller, B.J., Armstrong, D.J. and Skoog, F. (1977) Plant Physiol. 60, 197-202.

[20] Barciszewski, J., Otzen, D., Rattan, S.I.S. and Clark, B.F.C (1992) Biochem. Int. 28, 805-811.

[21] Matijasevic, Z., Sekiguchi, M. and Ludlum, D.B. (1992) Proc. Natl. Acad. Sci. USA 89, 9331-9334.

[22] Demple, B. and Harrison, L. (1994) Annu. Rev. Biochem. 63 , 915- 948.

[23] Inze, D. and Van Montagu, M. (1995) Curr. Opin. Biotech. 6 , 153-158

[24] Goldstein, S. and Czapski, G. (1991) Free Red. Commun. 12-13, 173-177.

[25] Frimer, A.A., Aljadeff, G. and Ziv, J. (1983) J. Org. Chem. 48, $1700-1705$.

[26] Innove, H. and Hirobe, M. (1986) Biochem. Biophys. Res. Commun. 137, 372-377. 